\title{
MARS 2000
}

\author{
Arden L. Albee \\ Division of Geological and Planetary Sciences, California Institute of Technology, \\ Pasadena, California 91125; e-mail: aalbee@cco.caltech.edu
}

\section{Key Words Mars, Mars Global Surveyor}

Abstract Twenty years after the Viking Mission, Mars is again being scrutinized in the light of a flood of information from spacecraft missions to Mars, the Hubble Space Telescope, and the SNC meteorites. This review provides an overview of the current understanding of Mars, especially in light of the data being returned from the Mars Global Surveyor Mission. Mars does not now have a global magnetic field, but the presence of crustal anomalies indicates that a global field existed early in Martian history. The topography, geodetic figure, and gravitational field are known to high precision. The northern hemisphere is lower and has a thinner and stronger crust than the southern hemisphere.

The global weather and the thermal structure of the atmosphere have been monitored for more than a year. Surface-atmosphere interaction has been investigated by observations of surface features, polar caps, atmospheric dust, and condensate clouds. The surface has been imaged at very high resolution and spectral measures have been obtained to quantify surface characteristics and geologic processes. Many questions remain unanswered, especially about the earliest period of Mars' history.

\section{INTRODUCTION}

Observed from the earliest days of humankind as a wandering star in the sky, Mars was a god to many civilizations, its menacing red color associated with blood and war. Mars has long been a part of human history, thought, and fiction. Eventually, optics revealed two tiny moons, an atmosphere, clouds and dust storms, and polar caps that diminished and expanded periodically during the twoyear Mars year. The nineteenth-century fascination with Mars was stimulated by the idea that life might exist there and that humans might eventually visit the planet. Early in this century, it was widely believed that advanced civilizations had developed on Mars, and that linear features seen by many observers were canals built to carry water from the polar caps to parched red equatorial deserts.

The perception of a planet hospitable to life changed dramatically with the advent of the Space Age. Beginning with the 1962 launch of the Soviet Union's Mars-1 spacecraft, 16 U.S. and Soviet missions had flown by, orbited, or landed on Mars prior to 1980. Before the current missions, most of what we know about 


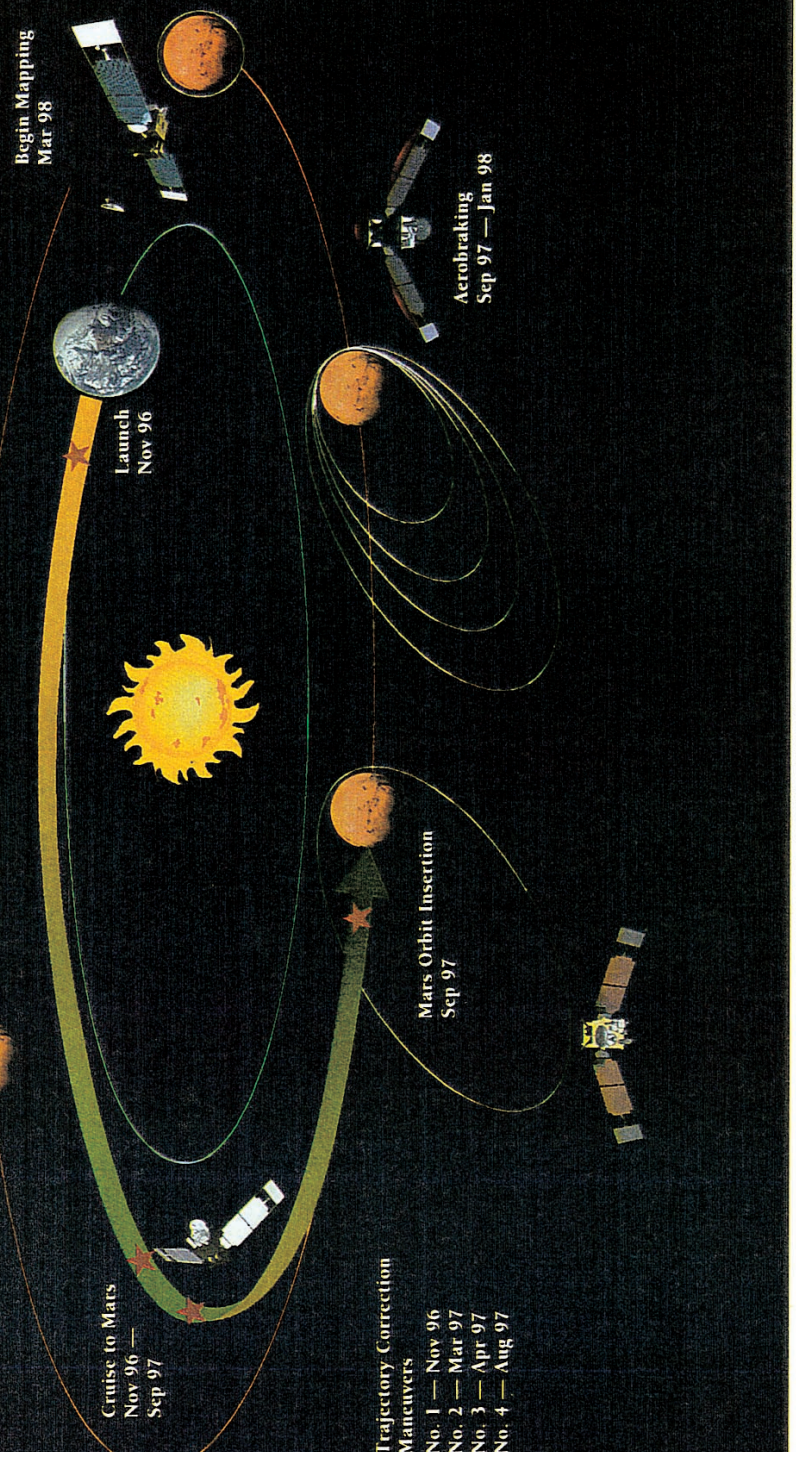




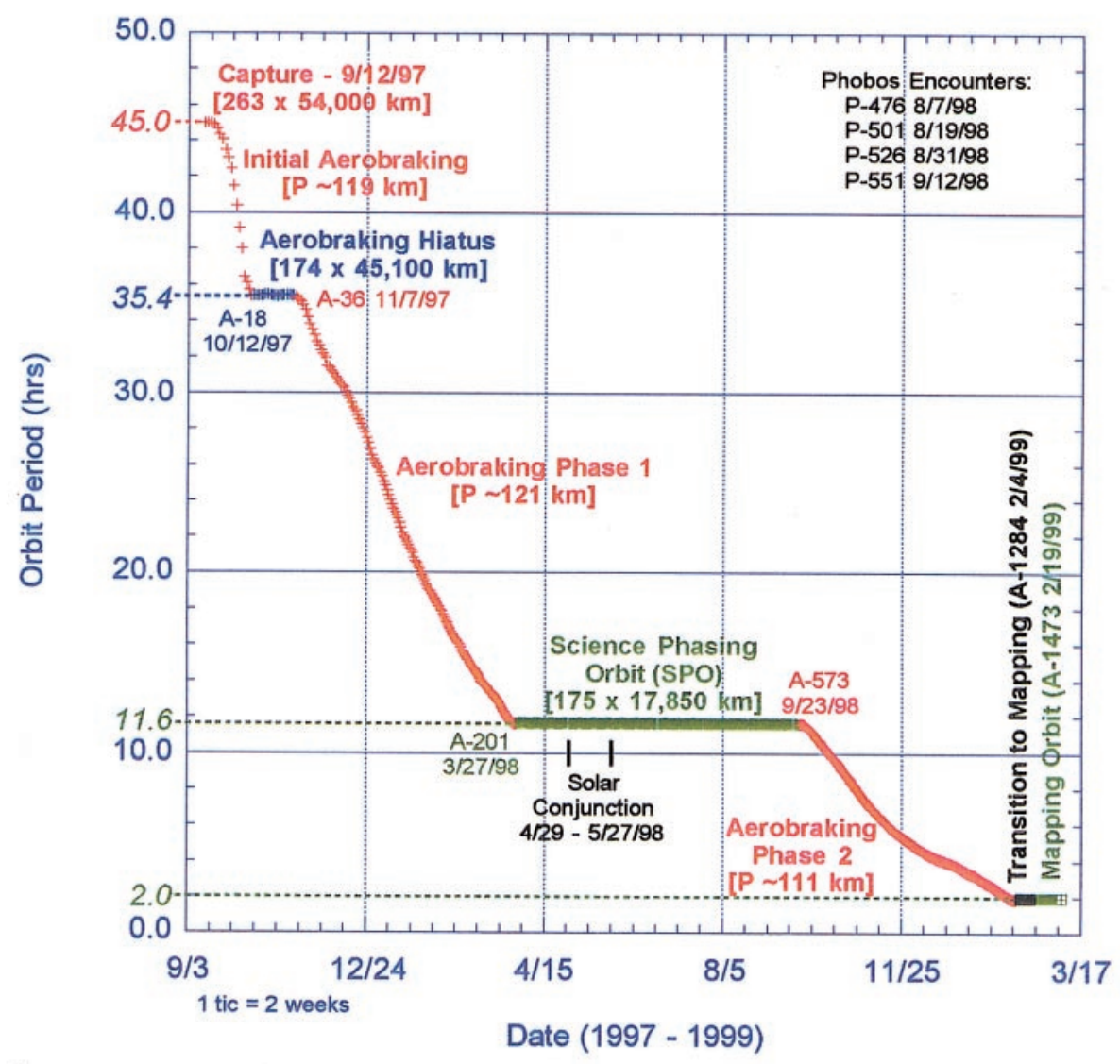

Figure 2 The unanticipated elliptical mission of Mars Global Surveyor. The orbit period steadily decreases with time during the aerobraking, but the orbit remains constant with a higher periapsis during the science phasing periods. 


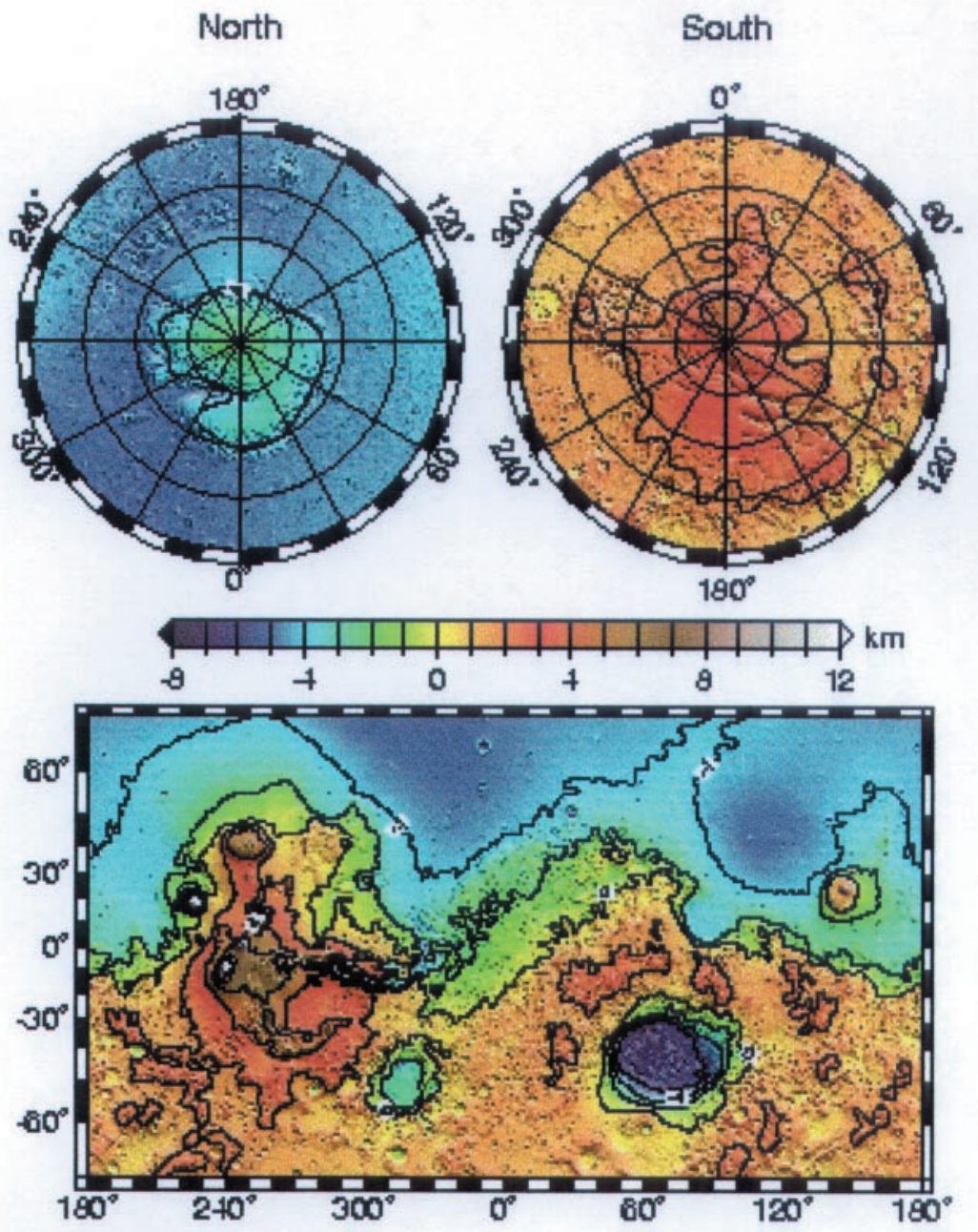

Figure 3 Map of the global topography of Mars as determined by the Mars Orbiter Laser Altimeter (Zuber et al 1999). The full-scale map has about 5-m accuracy with 118-km resolution. Major geographic features are labeled in Figure 5. 


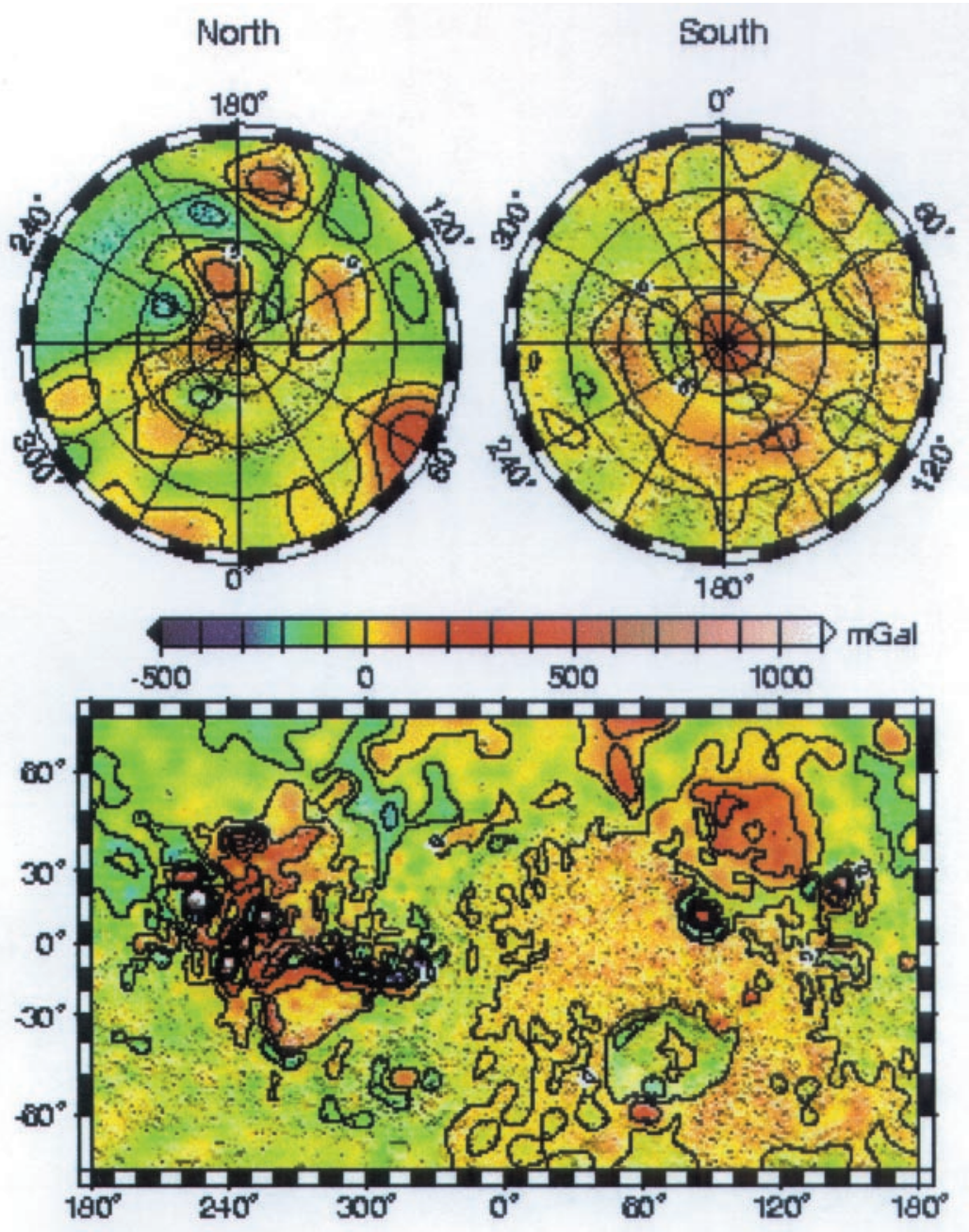

Figure 4 Map of the gravity field of Mars as determined by tracking of the Mars Global Surveyor spacecraft (Tyler et al 1999, Zuber et al 1999). The full-scale map has about $10-\mathrm{mGal}$ accuracy with 220-km resolution. Major geographic features are labeled in Figure 5. 


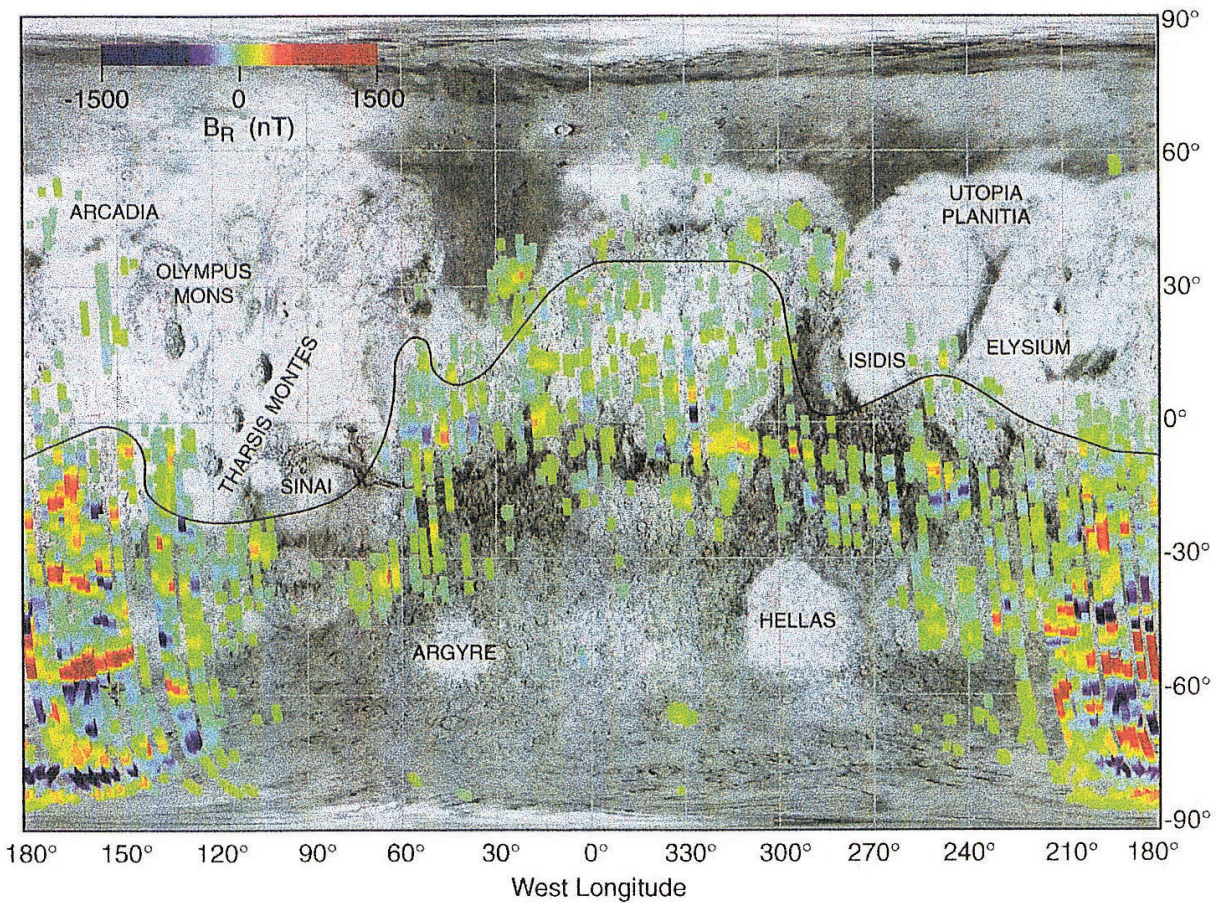

Figure 5 Map showing the location and intensity of crustal magnetism detected by the magnetic experiment on Mars Global Surveyor superimposed on an image of Mars (Acuna et al 1999). The radial component of the magnetic field is indicated by the color bars. It represents data acquired at altitudes between $100--200 \mathrm{~km}$ for 916 elliptical orbits. The solid line represents the dichotomy boundary. 


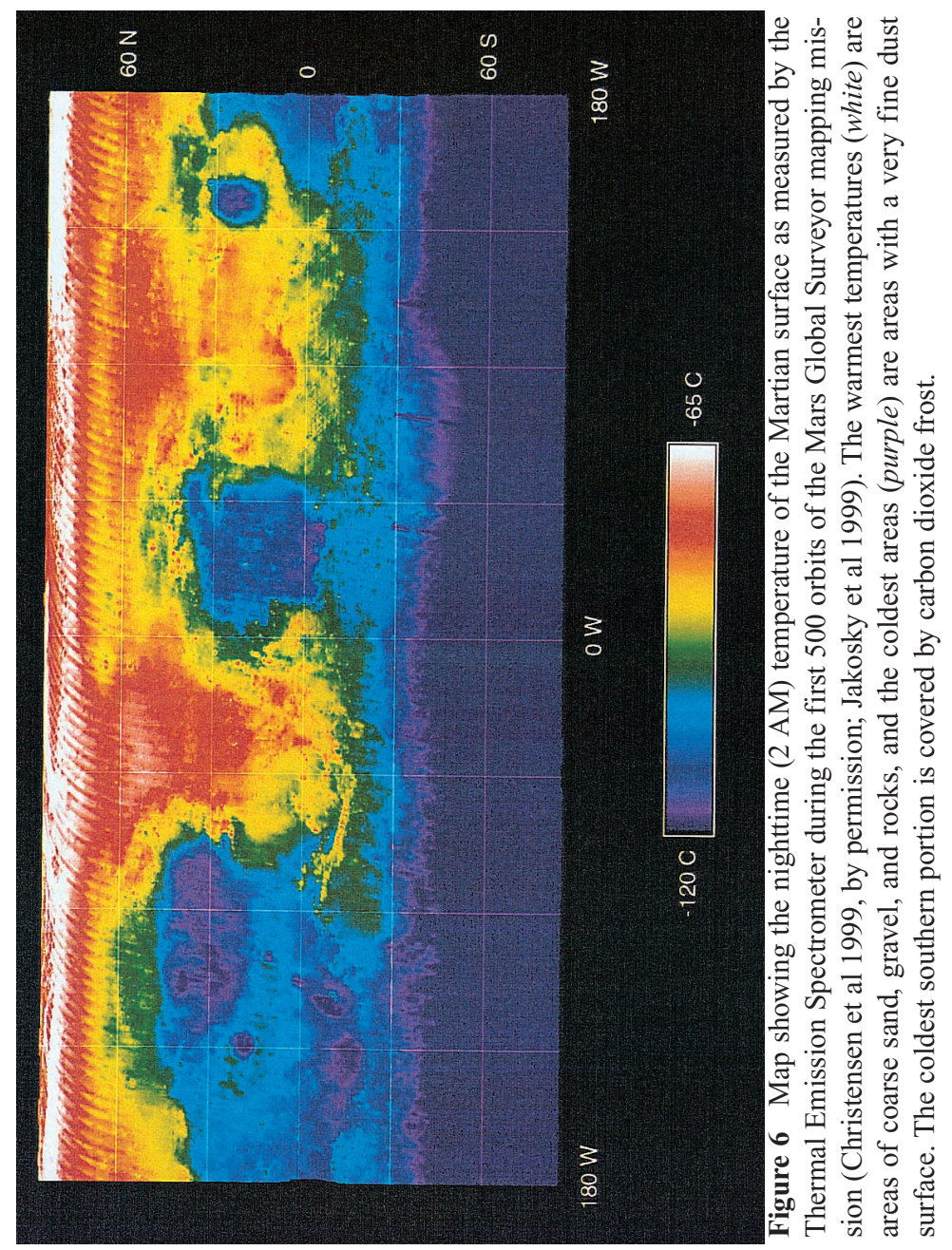



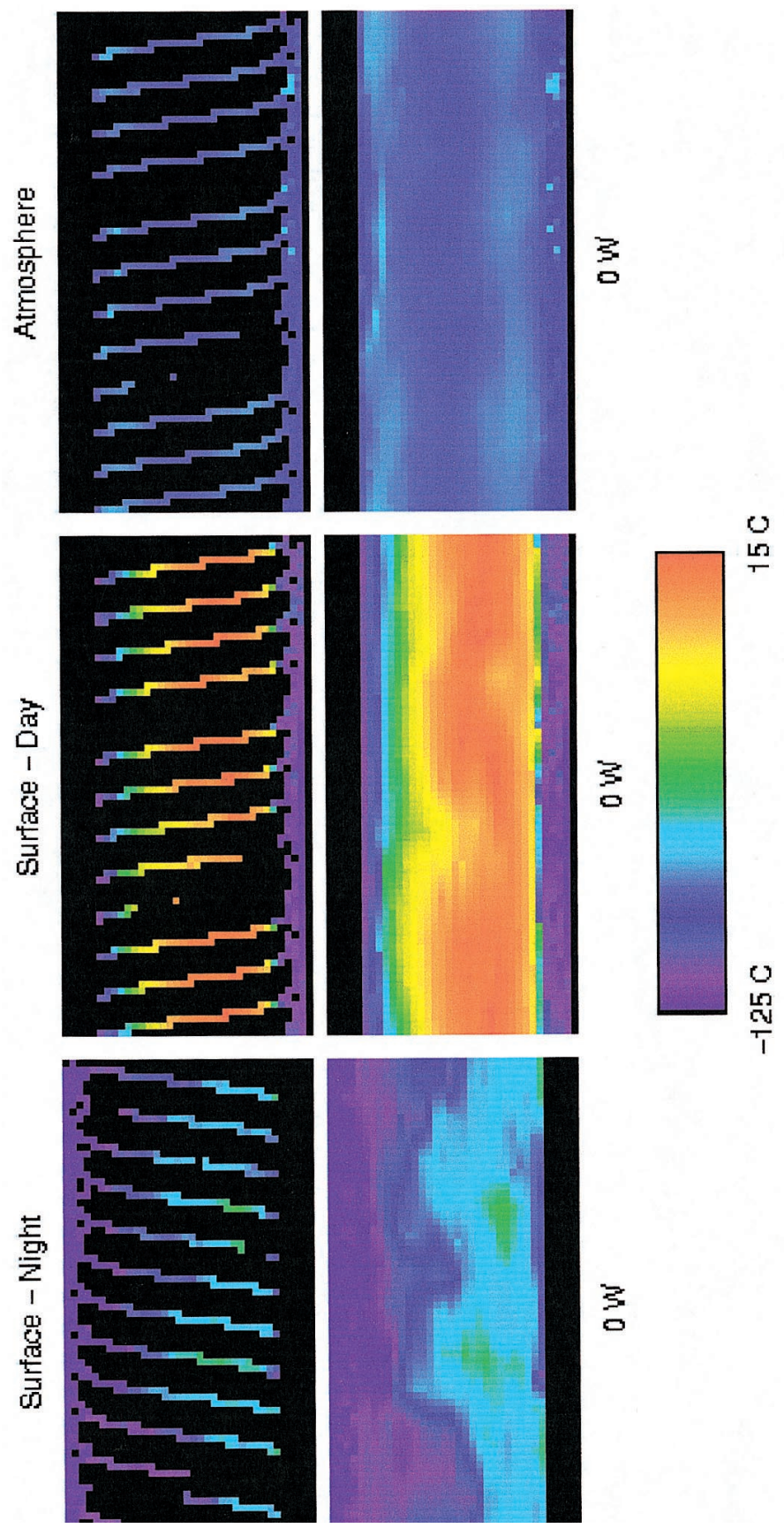

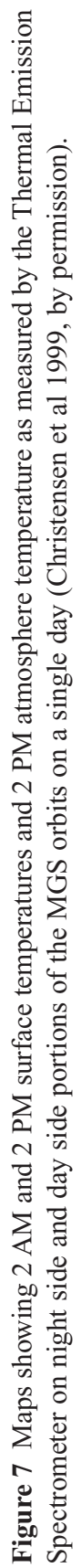


Mars came from Mariner 9, which began a one-year orbital survey of Mars in 1971, and Viking 1 and Viking 2, which were launched in 1975. Each Viking mission consisted of a lander and an orbiter, and data were returned until the loss of radio contact in 1982. These missions made spectacular discoveries, provided global information, and allowed the formulation of major questions about Marsthough many of the deepest questions remained unanswered.

By the early 1980s it was clear that the next mission to explore Mars would have to be much more comprehensive, providing long-term, global coverage in order to obtain answers to major remaining questions. This mission should make a variety of observations over at least one complete Mars year, studying the atmosphere, the surface, and the interior. Studies showed that this could be done economically by a spacecraft in a nearly polar orbit, carrying a suite of complementary instruments that would operate concurrently and continuously. The Mars Observer mission was developed to conduct these global studies; unfortunately, the spacecraft was lost in August 1993 just as it approached orbit insertion at Mars. In 1988, almost 13 years after the launch of the two Vikings, Phobos 1 and Phobos 2 were launched by the Soviets. Although this mission was short-lived, Phobos 2 returned significant data during its two months in Mars' orbit. In 1989 the Fourth International Conference on Mars convened, resulting in the publication of Mars (1992). This 1455-page volume provides "a source book on all aspects of Mars," including review chapters on the history of telescopic and spacecraft exploration of Mars. The latter chapter, pages 117-119, includes a comprehensive listing of special collections of scientific papers devoted to Mars missions or conferences. Preliminary results from the Phobos missions and the SNC meteorites are also included in the volume. The Fifth International Conference on Mars convened in July 1999 to provide an initial look at the new observations (Contribution 972, Lunar \& Planetary Institute, Houston, CD-ROM).

\section{HUBBLE SPACE TELESCOPE}

The Hubble Space Telescope was launched in April 1990. It was found to have spherical aberration in the primary mirror, but deconvolution techniques were developed that made it possible to study Mars because it has a large signal to noise ratio. Optical and spectral studies were carried out during the close approach of Mars in 1990 and have continued during subsequent oppositions (James \& Lee 1999). These studies provide synoptic coverage of the behavior of dust and condensates within the atmosphere and polar caps.

\section{SNC METEORITES}

The SNC meteorites can be considered as the collective science results of a spacecraft mission - which is entirely appropriate because each meteorite is a "space vehicle" that has been ejected from Mars and collected on Earth (McSween 1994, 
Longhi 1999). This group of meteorites, originally eight in number, had similar chemical, petrologic, and isotopic characteristics - and a younger age than that of most meteorites - that distinguished them from other stony meteorites. Around 1980, several groups of researchers concluded that Mars was their "least improbable parent body." This inference was substantiated in 1982 by the discovery (Bogard 1982) that shock-generated nodules within one sample contained a noble gas composition, unlike that in other meteorites or Earth, and very much like the pattern the Viking mass spectrometers measured for the Martian atmosphere. A torrent of subsequent papers only substantiated the conclusion that these meteorites were samples from Mars and that their characteristics must play a key role in any discussion on the origin and evolution of Mars.

McKay et al (1996) proposed that Martian meteorite ALH 84001 contains biochemical markers, biogenic minerals, and microfossils, which are relics of ancient Martian life. This announcement initiated a new flood of research-and controversy - that has not yet died down (McKay et al 1999, Treiman 1999). Correct or not, the resulting new research, based on remarkable analytical complexity, has focused attention once again on the possibility of extraterrestrial life. It is within the realm of possibility that Mars once harbored microorganisms. NASA's planned exploration program will address the question of life, among other topics, over the next decade.

\section{MARS PATHFINDER MISSION}

Mars Pathfinder landed on the surface of Mars on July 4, 1997, deployed and navigated a small rover, and collected data from three science instruments and ten technology experiments. As the first of the low-cost Discovery missions, it was designed primarily as an entry, descent, and landing demonstration (Golombek 1997). However, it operated on the surface for three months-capturing the imagination of the public - and returned over 17,000 lander and rover images, 16 chemical analyses of rock and soil, and 8.5 million temperature, pressure, and wind measurements (Golombek et al 1999; see also special issues J. Geophys. Res. 1997, 102:3953-4229, Science 1999, 278:1734-73). In addition to data obtained on the lander, radio tracking of the lander fixed its location in inertial space, fixed the spin pole of Mars, determined the precession rate for the period since Viking, and provided a polar moment of inertia that constrains the size of a central metallic core for Mars (Folkner et al 1997).

\section{MARS GLOBAL SURVEYOR MISSION}

Mars Global Surveyor (MGS) is the first of the missions in the Mars Surveyor Program, a program that will first realize and then go beyond the objectives of Mars Observer (Albee et al 1992, 1998). The Mars Global Surveyor spacecraft 
used spare components and science instruments from Mars Observer in a configuration only about half Mars Observer's size, and was launched on a smaller launch vehicle. Consequently, the two heaviest instruments from Mars Observer had to be accommodated on later missions in the program. In addition, as shown in Figure 1 (see color insert), the mission plan required about four months of aerobraking, using repeated dips into the upper atmosphere, to slow the spacecraft down from its initial 45-hour elliptical orbit to the final 2-hour, near-circular mapping orbit. Large solar array panels extend from each side of the spacecraft and provide the aerobraking drag. The mapping orbit is near circular and near polar, is sun-synchronous, and has a 117-minute period with a 7-day near-repeat cycle. As a result, the planet is repeatedly mapped in 26-day cycles with a constant sun angle (2:00 AM, 2:00 PM), permitting differentiation between the characteristics that vary daily and those that are due to seasonal changes. No movable scan platform is provided, as in most past missions. During the mapping configuration at Mars the spacecraft is continuously nadir-pointed, rotating at the orbital rate, as the antenna tracks Earth and the solar arrays track the Sun. Measurements are made continuously from the mapping orbit over the 687-day Martian year, which permits repetitive observations of the surface and gravity field and seasonal variations of the atmosphere and magnetic field.

The experiments include: Mars Orbiter Camera (MOC), a system of three linescan cameras; TES, a Thermal Emission Spectrometer; Mars Orbiter Laser Altimeter (MOLA), a laser altimeter; Radio Science (RS), using the spacecraft radio system as controlled by an ultrastable oscillator; MAG-ER, dual MAGnetometers complemented with an Electron Reflectometer; and Mars Relay (MR), a radio communication system to relay data to Earth from landers on the surface of Mars. Each of the instruments and the purpose of each experiment are described in separate papers in a special issue (1992, J. Geophys. Res. 97:7663-814).

MOC is currently photographing portions of Mars at unprecedented resolution, looking at the surface effects of wind, water, ice, volcanic eruption, earthquake faulting, slope failures, and other geological processes. The narrow-angle camera can capture small areas at its highest resolution of $1.4 \mathrm{~m}$ per pixel, but because of the high data volume required, only small "samples" (postage stamps) can be imaged at this resolution. Features as small as 3-4 m across-such as boulders, craters, and dunes - are recognizable, and evidence of the action of surface processes is visible in every high-resolution image. MOC also scans the entire planet daily with the red and blue wide-angle cameras in order to build up synoptic coverage of the surface and atmosphere, much like Earth-orbiting weather satellites. These cameras also image targeted strips at a medium resolution and will produce color stereoimagery of the entire surface over the course of the mission.

TES uses a Michelson interferometer that measures the emitted infrared spectrum at high spectral resolution to determine the mineral composition and thermal properties of Martian rocks and soils and the composition of ices, atmospheric dust, and clouds. TES continuously measures temperature and pressure profiles 
in the atmosphere from pole to pole, providing clues to atmospheric dynamics and to the energy balance of the Martian surface and atmosphere.

MOLA uses the flight time of a laser pulse from the spacecraft to the surface and back, in conjunction with knowledge of the spacecraft position, to map the shape and topography of Mars with a precision of better than ten meters. The laser fires ten pulses per second, illuminating a $\sim 160$-m circle on the surface. RS uses data provided by the spacecraft's radio system and an onboard ultrastable oscillator to map spatial variation in the gravity field of Mars, by measuring instantaneous velocity changes of the spacecraft in its orbit. The gravity data are used with the topographic data to determine the structure of the Martian crust, thereby providing important insights into the evolution of the interior. In addition, as the radio transmission from the spacecraft passes through the Mars atmosphere it is diffracted by the atmospheric electrons and provides high vertical resolution profiles of the temperature and pressure in the atmosphere.

The MAG investigation measures the magnetic field on Mars. The presence of a magnetic field provides direct evidence for the existence of active motions in a fluid core, either at the present or at some time in the past. The electron reflectometer measures electronic properties as the spacecraft passes through the upper atmosphere, and can infer the presence of weak remnant crustal magnetization, which may be indicative of changes in the magnetic field over geologic time. The spacecraft accelerometer and the horizon sensor are being used as additional atmospheric sensors during the aerobraking period.

The MGS spacecraft was launched on November 7, 1996. After orbital insertion into a 45-hour elliptical orbit at Mars on September 11, 1997, MGS entered a period of aerobraking, using repeated dips into the upper atmosphere to slow it so as to attain the low-altitude $(378 \mathrm{~km})$ circular-mapping orbit. According to plan, it would have reached this orbit early in spring of 1998. However, the failure of a solar panel damper during deployment in early cruise resulted in damage to a panel, the extent of which did not become clear until about a month into aerobraking. At that time, the orbit was raised higher in the atmosphere to lower the pressure on the panel, and the science instruments were operated in their preferred nadir orientation in the near-periapsis portion of each 35.4-hour elliptical orbit for a month during assessment of the problem. In these 16 orbits the periapsis altitude was only $174 \mathrm{~km}$, and the spacecraft passed in and out of the ionosphere on each orbit. Excellent (though unanticipated) science data were acquired during this period, as alternative plans were considered (Science, special issue, 1998, 279:1671-97). The revised mission plan delayed entry into the circular mapping orbit for an entire Martian year, requiring many more aerobraking dips into the atmosphere, but with only one third as much pressure being exerted on the solar panels as in the original plan. The details of aerobraking orbits and of science phasing orbits are summarized in Figure 2 (see color insert). The spacecraft finally reached the 378-km circular orbit on February 19, 1999, but in the 2:00 AM (relative to the sun) position rather than in the originally planned 2:00 PM position. This delay was undertaken because it made it possible to operate the spacecraft 
and its instruments in the geometric relationships for which they had been designed.

Scientific observations were obtained during most of this period of delay. Lowaltitude (high-resolution) data, especially important for the magnetometer and gravity investigations, were obtained over most of the planet. Such coverage was possible because during this period of time, the periapsis position of the continuously decreasing elliptical orbit migrated from $45^{\circ}$ north over the north pole and then down and over the south pole. Correct phasing of the entry into the circular orbit necessitated a pause in the aerobraking operation, during which science data were collected from 372 elliptical orbits, $175 \mathrm{~km}$ by 17,850 km, from March 27, 1998 to September 23, 1998. During the periapsis portion of each 11.6-hour orbit, the spacecraft was turned to the nadir-pointing position so that the instruments pointed to Mars for about 22 minutes. The altimeter, thermal emission spectrometer, and camera obtained data in near-normal mode during the nadir portion of these orbits and acquired lower-resolution global image and thermal data during the rollout from the nadir position to the Earth-point position. The magnetometerelectron reflectometer obtained data throughout the entire orbit during most of this period, but radio tracking was limited.

Science data were also obtained during the aerobraking orbits. The atmospheric density of Mars at the aerobraking altitude demonstrated great variation over time as well as large orbit-to-orbit differences. So that the spacecraft could adjust its orbit, the density had to be predicted for each orbit to determine the appropriate and safe depth within the atmosphere for the aerobraking passage. Although science data acquisition during the aerobraking phase was not in the original mission plan, MOC, TES, the accelerometer, the electron reflectometer, and the horizon sensor all acquired data to support prediction of the atmospheric density. In addition, images from the Hubble Space Telescope and ground-based whole-disk microwave observations were used. During the aerobraking passage through the atmosphere, the spacecraft had the solar panels in a V-configuration with the instrument panel in the lee direction. The accelerometer data provided density profiles of this atmospheric passage. At the end of aerobraking, as the spacecraft exited the atmosphere, it rolled to point the main antenna toward Earth. During this roll, MOC and TES obtained visual and thermal coverage of much of Mars. MAG-ER data were acquired throughout each orbit. Gravity measurements and atmosphere profiles were obtained from radio tracking and accelerometer measurements during the aerobraking orbits. MGS returned 2,140 MOC images, 11 million TES spectra, 206 MOLA profiles with 2.6 million points, 465 radio-occultation profiles, and 1000 MAG low-altitude passes during this unexpected bonus before the primary mission. Moreover, atmospheric data were obtained over a range of daily times, other than the fixed 2:00 AM/PM positions of the mapping mission.

After a period of orbit adjustment, instrument calibration, gravity measurements, and acquisition of a seven-day data set from all instruments, the high-gain antenna (HGA) was deployed on its boom from the fixed position attached to the 
body of the spacecraft. This deployment permitted initiation of the planned mapping mission, which requires the HGA to track Earth and return data simultaneously with data taken by the instruments. Unfortunately, the motion of the HGA azimuth gimbal is being limited by an obstruction of some kind. This restriction of the motion of the HGA will not permit simultaneous Earth tracking and data acquisition after February 2000. The potential work-arounds will increase the data rate, but not to the planned level. Currently, data are being returned at a very high rate and are being archived for electronic public access by the Planetary Data System (http://www.pds.jpl.nasa.gov). Published collections of early results from Mars Global Surveyor are: Science 1998 279:1597-1816; Geophys. Res. Lett. 1998 25:4393-420; Science 1999 284:1495-502; Nature 1999 397:584-94; J. Geophys. Res. Planets 1999, in press.

\section{FUTURE NEAR-TERM MISSIONS}

Mars Global Surveyor is only the initial mission in the NASA Mars Surveyor Program. This program consists of a series of missions to explore Mars and it was initiated upon the loss of Mars Observer in 1993. Over the next decade, the Mars Surveyor Program will launch orbiters or landers every 25 months, using advanced technology to develop a comprehensive portrait of Mars. The program focuses on understanding present and past climatic conditions on Mars, determining whether Mars developed prebiotic compounds and life, and identifying resources that might be of use during human expeditions to the surface. Determining the locations and states of water reservoirs now and in the past are key objectives. Extension of rover capability will lead to sample selection and collection, and may lead to a sample being returned to Earth for study before 2010 . International participation and collaboration is involved, as well as independent missions by other nations.

Three missions were launched in 1998. The Japanese Mars orbiter Planet B (Nozomi) mission was launched on July 4, 1998. The main objective of this mission is to study the interaction of the Martian ionosphere with the solar wind from an elliptical orbit with a periapsis altitude of $150 \mathrm{~km}$ and an apoapsis distance of 15 Mars radii. Nozomi was due to arrive at Mars in late 1999, but encountered a problem on an engine firing. According to a new mission plan, however, Nozomi will make three rotations around the sun and two Earth swingbys, and will arrive at Mars on January 1, 2004 to carry out its planned mission. During the intervening period it will serve as an interplanetary particles and fields probe (Tsuruda 1999).

The Mars Climate Orbiter was launched on December 11, 1998 and was to enter Mars's orbit on September 23, 1999; it was to use atmospheric instruments and cameras over a Martian year to provide information about the climate of Mars. Unfortunately, it did not achieve a successful orbit at Mars. Its companion, the Mars Polar Lander, was launched on January 3, 1999 and will land on Decem- 
ber 3, 1999 near the edge of the south polar cap. The lander is equipped with cameras, a robotic arm, and instruments to study the Martian soil composition. Two small microprobes are also being carried on the lander mission and will penetrate into the Martian subsurface to detect water ice. ${ }^{1}$

On March 30, 2001 an orbiter will be launched with a gamma ray spectrometer, the last of the Mars Observer instruments, to carry out global mapping of the elemental composition of the surface and to determine the abundance of hydrogen in the shallow subsurface. A combined high-resolution camera and thermal infrared imaging spectrometer will map the mineralogy and morphology of the surface, and the radiation environment will be characterized. A companion lander will be launched on April 10, 2001 and will land on January 22, 2002. It will carry instruments and technology experiments that will provide insight into decisions regarding future missions to Mars, including sample return.

\section{UNDERSTANDING OF MARS}

\section{Introduction}

A summary of some key facts about Mars provides a useful introduction to a discussion of our current understanding. Mars has a much larger and much more elliptical orbit than does Earth, but has a length of day very close to Earth's (24 hours and 37 minutes) and a $25^{\circ}$ tilt to the orbital plane, which is close to Earth's $\left(23.3^{\circ}\right)$. As a result, the Martian year is nearly twice as long as the Earth year (687 Earth days) and its seasons are unequal in length, with the southern summer being shorter than the northern.

Mars is about $6800 \mathrm{~km}$ in diameter, about half the diameter and about one eighth the volume of Earth. The surface area is close to the amount of the land area on Earth. The force of gravity at the surface is only $38 \%$ of that on Earth. The atmosphere is $95 \%$ carbon dioxide, with small amounts of nitrogen and oxygen and trace amounts of water. The atmospheric pressure is less than $1 \%$ of that on Earth and varies by about $25 \%$ as either the southern or northern polar frost cover expands or contracts. Because the thin atmosphere has a low heat capacity, the surface temperature varies from $\sim+27$ to $\sim-133$ Celsius, virtually from day to night. Liquid water cannot exist at the surface under present pressure and temperature conditions-water ice sublimates into water vapor without the formation of liquid water. However, water ice can exist at some depth within the regolith over much of the planet, during all or much of the year. Surprisingly, this thin atmosphere has a complex circulation and dynamics with a wide variety of weather phenomena: winds, high-level ice clouds, low-level fogs, frost, dust devils, and massive dust storms. Periodically, Mars has planet-encircling dust storms, typically starting in the short southern spring. Dunes, sand sheets, and wind-

\footnotetext{
${ }^{1}$ Note added in proof: Unfortunately, no transmission was received from the landers or the microprobes.
} 
carved rock features also give evidence of aeolian activity. The overall circulation and dynamics of the atmosphere show many similarities to-and many differences from-Earth. They are dominated by the seasonal and climatic cycles of carbon dioxide, water, and dust. The permanent polar caps are water ice intercalated with dust, and the seasonal caps are carbon dioxide frost or ice.

Mars can be divided roughly at the equator into two very different terrains. The southern hemisphere is an ancient, Moon-like, heavily cratered highland, preserving records of the period about 4.6-3.9 million years ago when all the terrestrial planets were bombarded with chunks of debris. The younger and lower northern plains or lowlands contain abundant evidence of more recent volcanic, tectonic, and erosional activity. Most of the plains are probably covered with multiple layers of volcanic flows, with a number of immense volcanic constructs with calderas marking their summits. Systems of fault patterns mark the Tharsis uplift. The immense canyon Valles Marineris, just south of the equator, is more than $5000 \mathrm{~km}$ long and debouches northward into the northern plains. Chaoticpatterned head regions mark it and other channels that empty into the northern plains, which indicates a source from subterranean water or ice. The shapes and structures of these channels indicate, almost without a doubt, that they were carved by running water. Although these channels may have formed by floodwaters derived from subterranean sources, the patterns of other, much smaller dendritic valley networks as seen by Viking suggest that they were formed by surface runoff, possibly indicative of rainfall.

Where has this water gone, given that it cannot currently be present as liquid at the surface? Only a small amount is present in the polar caps and the atmosphere. Is it hidden in permafrost layers beneath the surface, or did it escape to space? Was there a period in Mars' history when the atmosphere had sufficient carbon dioxide that the pressure was great enough to stabilize liquid water on the surface and in the atmosphere? This, in turn, would imply the loss of tremendous amounts of carbon dioxide, either into space or into carbonates on the surface of Mars. These are critical questions. Liquid water is fundamental to the understanding of geological processes and climate change, and of course it is essential for the life forms that we know.

Given this understanding about Mars, the MGS science objectives were closely coupled to the measurement capabilities of MGS, which were directed toward answering major questions about Mars. It then follows that these objectives, listed below, represent important directions in which new measurements have been recently obtained, and are major topics in the following discussion of the current understanding of Mars:

- Characterize surface morphology at high spatial resolution to quantify surface characteristics and geological processes.

- Determine the composition and map the distribution of surface minerals, rocks, and ices, and measure surface thermophysical properties.

- Determine globally the topography, geodetic figure, and gravitational field. 
- Establish the nature of the magnetic field and map the crustal remnant field.

- Monitor global weather and thermal structure of the atmosphere.

- Study surface-atmosphere interaction by monitoring surface features, polar caps, polar thermal balance, atmospheric dust, and condensate clouds over a seasonal cycle.

\section{The Martian Interior}

Very early in the MGS mission, the evidence from the magnetometer experiment showed that Mars lacks a global magnetic field at the present time (Acuna et al 1998). This resolved a long-standing controversy, and places an important constraint on the nature of the existing Martian core. More importantly, however, the magnetometer has mapped crustal magnetic anomalies of surprisingly high strength in the older rocks of the southern hemisphere, and these anomalies are interpreted as evidence of an early vigorous convecting dynamo in the core. Such a vigorous early dynamo would be consistent with isotopic evidence from the Martian meteorites that indicates early core-mantle separation.

Our knowledge of the structure and composition of the Martian interior is limited by the absence of any seismic data. The strongest geophysical constraints are knowledge of the mass and radius of the planet and the moment of inertia factor. The strongest geochemical constraints are derived from the SNC meteorites. Inferences drawn from knowledge of the gravity and magnetic fields, the topography, and the timing of extensive volcanism are less direct, but also important.

Using the mass and radius of the planet and the moment of inertia factor as constraints, two of the three variables-mantle density, core size, and core density - can be calculated as a function of the third. Folkner et al (1997) reported an improved value for the moment of inertia factor, based on the Martian spin pole recession rate determined from Doppler and range measurements to the Mars Pathfinder lander, $0.3662 \pm 0.0017$. This provides an important new constraint on the interior of Mars.

Dreibus \& Wanke (1985) derived a Martian mantle and core composition with a model that did not require using the constraint of the moment of inertia factor; this factor could then be used as a test of the model. Different processes-igneous differentiation, nebular condensation, core separation, etc-differentially change the ratios of particular element pairs. Using such comparisons, many authors have concluded that the SNC parent body (Mars) has higher abundances of moderately volatile elements (alkalis, sulfur) than Earth, and possibly higher abundances of carbon and water. Similarly, $\mathrm{Mn} / \mathrm{Mg}$ is nearly constant in ordinary and $\mathrm{C} 1$ chondrites, and $\mathrm{Fe} / \mathrm{Mn}$ varies little during igneous processes; therefore, if the silicate portion of a planet has chondritic proportions of refractory elements $(\mathrm{Ca}, \mathrm{Al}, \mathrm{Ti}$, $\mathrm{Mg}, \mathrm{REE})$ then $\mathrm{Fe} / \mathrm{Mn}$ in derived basalt can provide an estimate of $\mathrm{Fe} / \mathrm{Mg}$ for the bulk silicate portion of the planet. Dreibus \& Wanke (1985) used correlations between measured element ratios in the SNC meteorites and chondritic abun- 
dances to derive a mantle composition with all oxyphile refractory elements present in $\mathrm{C} 1$ chondrite abundance ratios, and a bulk planet composition with the $\mathrm{Fe} /$ $\mathrm{Si}$ ratio of a $\mathrm{C} 1$ chondrite. They derived a value of 0.75 for $\mathrm{Mg} / \mathrm{Mg}+\mathrm{Fe}$ for the silicate crust and mantle. A bulk S content for the planet was calculated from volatile element systematics, and other abundances were used to infer that FeS liquid had scavenged certain elements out of the early mantle and into the core. These calculations led to the conclusion that Mars has a core of $14.5 \% \mathrm{~S}$ with a radius of $1690 \mathrm{~km}$, about half the total radius of Mars (Longhi et al 1992, Longhi 1999).

The D-W mantle composition has been used as a basis for high-pressure experiments (Bertka \& Fei 1997) to determine the changes in mineral phases down to the core-mantle boundary along a model PT profile of the Martian interior. Using the results of their experiments, Bertka \& Fei (1998a,b) calculated a mantle density profile for the DW model and then calculated the moment of inertia factor as a function of core composition and crustal thickness. More recently (1999), they have discussed these results in light of the new and more precise moment of inertia factor reported by Pathfinder. They show that by using a D-W core with $14.5 \% \mathrm{~S}$ and a DW mantle with $\mathrm{Mg} / \mathrm{Mg}+\mathrm{Fe}$ of 0.75 , along with the new moment of inertia factor, they obtain a result of $\sim 50 \mathrm{~km}$ crust with a density of $3.0 \mathrm{gm} /$ $\mathrm{cm}^{3}$. However, the $\mathrm{Fe} / \mathrm{Si}$ is much lower (1.32) than the $\mathrm{D}-\mathrm{W}$ value, as is the core radius (1420 rather than $1690 \mathrm{~km}$ ). Maintenance of a $\mathrm{C} 1 \mathrm{Fe} / \mathrm{Si}$ ratio would require that the D-W model include a much thicker crust $(180-320 \mathrm{~km})$ and a lower crustal density (2.7-3.0). Bertka \& Fei (1999) conclude that the Fe/Si ratio and the bulk Fe content of Mars are not those of $\mathrm{C} 1$ chondrites, and that this eliminates the possibility that all terrestrial planets were accreted from $\mathrm{C} 1$ materials. However, a mixture of carbonaceous chondrites with ordinary or enstatite chondrites could produce a bulk planet composition consistent with geophysical and geochemical constraints (i.e. the D-W model).

The high S content of the D-W core composition has also inspired highpressure work in the Fe-Ni-S system (Pike et al 1999). Bertka \& Fei (1999), using the D-W mantle and core composition and the new moment of inertia factor, calculated a pressure of $25 \mathrm{Gpa}$ at the top of the core. At this pressure, the high $\mathrm{S}$ core composition would start to melt at $1125^{\circ} \mathrm{C}$ and would be completely molten at $1500^{\circ} \mathrm{C}$. Current thermal models for Mars indicate that the temperature at the core-mantle boundary is higher than $1500^{\circ} \mathrm{C}$. Therefore, it is likely that Mars has a sulfur-rich fluid core, which would be consistent with the lack or near-lack of a global magnetic field.

\section{The Martian Crust}

The most distinctive and enigmatic feature on the surface of Mars is the hemispheric dichotomy between the old, highly cratered southern highlands and the younger, lightly cratered northern plains. The laser altimeter on MGS has now provided a precise map of the shape and topography of Mars. The global 
topography of Mars is now known to greater accuracy than Earth's continents in a root mean square sense (Smith DE et al 1999a). The ellipsoidal shape is flattened by $\sim 20 \mathrm{~km}$ because of rotation, and the center of figure is offset by $2986 \mathrm{~m}$ along the polar axis, indicating that the north pole is about $6 \mathrm{~km}$ lower than the south pole. As pointed out by Bills \& Ferrari (1978), this offset requires that the density distribution for Mars is not radially symmetric and is consistent with a thicker crust in the southern highlands. In addition, the center of figure is offset $\sim 1428$ $\mathrm{m}$ toward the Tharsis topographic rise.

As shown in Figure 3 (see color insert; Smith DE et al 1999a, Zuber et al 1999), the topography of Mars has a range of $30 \mathrm{~km}$ from the lowest point in Hellas to the top of Olympus Mons-the largest range of any terrestrial planet and much larger than the 20-km range of Earth. The full-scale map has about $5-\mathrm{m}$ accuracy for $118-\mathrm{km}$ resolution. The most striking feature remains the $\sim 5-\mathrm{km}$ difference in elevation and the difference in roughness between the smooth northern plains and southern cratered highlands. The northern lowlands are exceedingly smooth and level, and if Mars had running water, the northern lowlands would drain a watershed of nearly three-quarters of the planet's surface (Smith DE et al 1999a). Huge volcanic constructs mark the vast Tharsis plateau that sits astride the dichotomy boundary, and the Hellas and Argyre basins indent the southern highlands. The Hellas impact basin has a total relief of more than 9 $\mathrm{km}$, the deepest topography on Mars. The main basin, with a diameter of $\sim 2300$ $\mathrm{km}$, is surrounded by a highly cratered higher annulus lying $\sim 2 \mathrm{~km}$ above the edge of the main basin. Material thrown out from Hellas accounts for a significant contribution to the higher topography of the southern hemisphere.

The hemispheric dichotomy marks both a difference in elevation and a difference in surface geology. Various hypotheses to explain these differences have included thinning of the northern hemisphere crust by mantle convection, an early period of tectonic plate recycling, and large impacts in the northern hemisphere. The new topographic data demonstrate that the offset between the center of figure and the center of mass accounts for much of the elevation difference between the two hemispheres; it further indicates that the hemispheric elevation difference is primarily a long-wavelength effect that may be due to large-scale differences in the crustal thickness (Smith DE et al 1999a). Smith DE et al (1999a) suggest that "the dichotomy boundary as manifest in surface geology and regional topography appears to contain three dominant contributions: i. Volcanic constructions associated with Tharsis, ii. Major excavated deposits approximately circumferential to Hellas, with additional contributions from Isidis and probably Utopia ejecta, and iii. Modification of the intervening region by fluvial processes associated with the outflow channels that empty into Chryse Planitia."

Knowledge of both the gravity field and the surface topography is key to understanding the internal structure of the planet. Removal of the gravitational signal of the topography makes it possible to gain some understanding of the internal density anomalies that are associated with thermal or compositional differences. New observations of the gravity field of Mars are shown in Figure 4 
(see color insert). The full-scale map has about 10-mGal accuracy for 220-km resolution (Smith DE et al 1999b, Zuber et al 1999). Together, Figures 3 and 4 show that the gravity anomalies correlate well with the principal features of the topography, including volcanic constructs, impact basins, and the Valles Marineris. However, the planet has responded differently in its northern and southern hemispheres to major impacts and volcanic processes. The rough, elevated southern hemisphere has a relatively smooth gravitational signature indicating a state of near-isostatic compensation, whereas the low, flat northern plains display a wider range of uncompensated gravity anomalies that indicate a thinner but stronger crustal layer than in the south. To first order, the 6-km difference in elevation from pole to pole can be accommodated by a crustal thinning of about $30 \mathrm{~km}$ from the south pole to the north pole. In general, the dichotomy does not have a distinct gravitational signature directly associated with it. Mascons, which are gravity highs associated with topographic lows, are present in the Argyre, Hellas, and Isidis basins. The northern hemisphere shows evidence of buried impact basins, though none are large enough to be used to explain the hemispheric elevation difference. The gravitational potential pattern of Tharsis is approximately axisymmetric and contains the Tharsis volcanoes, but the Olympus Mons and Alba Patera volcanoes seem to be adjacent, separate features. The gravity signature of Valles Marineris extends into Chryse and provides an estimate of material removed by early fluvial activity.

During the low altitude passes in the extended aerobraking period of MGS, the magnetometer mapped a number of large, linear, magnetic structures in Mars' southern hemisphere (Acuna et al 1999, Connerney et al 1999). Such features were not found in the northern lowlands, and no magnetic structures are associated with the major volcanic constructs or with Tharsis. This implies that the internal dynamo had ceased to operate by this time of formation of these structures.

As shown in Figure 5 (see color insert), parallel bands, $\sim 200 \mathrm{~km}$ by 1000 $2000 \mathrm{~km}$, show reversals in the radial magnetic field direction from inwardpointing to outward-pointing in adjacent bands. Some show a magnetic moment that is an order of magnitude greater than any known on Earth. The linear pattern, the reversal in polarity, and the size of the magnetic moment all present problems in interpretation that are not yet resolved. On Earth, linear magnetic patterns of alternating polarity are associated with sea floor spreading and repeated reversals of the global dipole field of Earth. Molten magma is injected from below, cools below its Curie temperature, and acquires a permanent remanent magnetic moment aligned with the terrestrial dipole field. The typical spreading rate and the typical reversal period lead to a characteristic width of $\sim 10 \mathrm{~km}$ for such features. By comparison, Mars would require a faster spreading rate or a longer period between magnetic reversals. The magnitude of the magnetic moment introduces other problems to such a simple explanation. The moment, which is the product of the magnitude and effective volume of coherent crustal magnetization, must be at least an order of magnitude greater than for crustal rocks on Earth. For strength of magnetization similar to terrestrial upper crust, the depth of coher- 
ent magnetization would have to be about $30 \mathrm{~km}$. This would require an exceedingly high rate of heat loss because the crust must cool to a temperature lower than the Curie temperature of the dominant magnetic mineral throughout this entire depth interval, on a time scale shorter than the interval between reversals. Alternate explanations require an unusually high concentration of the magnetic minerals or an exceedingly vigorous convection leading to a very strong dynamo. Acuna et al (1999) have suggested an alternative to reversals of the dipole field. A thin, highly magnetized plate, broken into linear blocks and separated by injection of material of lower magnetism, would show a similar pattern of reversals in the radial magnetic field at the orbital altitude. At this point, however, no fully satisfactory model is able to explain these new observations of the magnetic field.

No magnetic anomalies are associated with the Argyre, Hellas, or Isidis basins, which suggests that these impacts postdated the cessation of dynamo action. Furthermore, the linear magnetic pattern has been destroyed in the vicinity of Hellas, either through reheating above the Curie point or by mechanical destruction of the coherent magnetization. The 9-km relief of Hellas implies that the lithosphere at the time of the formation of Hellas was of substantial thickness and possessed long-term strength. Because Hellas and its ejecta are extensively modified by cratering processes, the magnetic and topographic evidence both suggest that the crust in the southern hemisphere had cooled rapidly enough to achieve a substantial thickness before the end of the period of heavy bombardment.

\section{The Upper Crust, Volcanism, and Tectonism}

The deluge of new, high-resolution images and laser altimetry profiles have not yet been assimilated well enough to provide substantial changes in general geologic thinking. Any attempt to review it in detail would be obsolete before this review is printed. The scientific payoff will occur when data from MOC, MOLA, and TES have been carefully studied and compared.

However, it is still believed, perhaps mostly for want of any better explanation, that most of the surface of Mars is of volcanic origin. In addition to the volcanic constructs with a wide range of sizes and styles, most of the northern plains appear to have been surfaced by volcanic rocks. The relative extent of flows and pyroclastic deposits, their composition, and other details will require systematic study of the new data. High-resolution images do show volcanic flow features in some places, but they also show that aeolian material mantles much of the surface, obscuring diagnostic features. Analysis of crater populations on the highresolution MOC images indicate that some lava flows within the Arsia Mons caldera are not older than 40-100 million years (Hartmann et al 1999). A recent detailed review of volcanism on Mars (Greeley et al 1999) concludes: "Despite more than three decades of exploration by spacecraft, many fundamental questions regarding Martian volcanism remain unanswered."

The Tharsis uplift region has striking patterns of faults, but the high-resolution images and topography are just beginning to be used in modeling to improve understanding of the tectonism of the uplift region. 
The MGS camera has shown (Malin et al 1998, McEwen et al 1999, Malin \& Edgett 1999a) that layering is very common in the upper crust of Mars, much more common than was generally acknowledged. A common view was that the heavily cratered terrain was like that of the Moon-a megabreccia of primordial crust. However, layered crust is exposed to a depth of almost $10 \mathrm{~km}$ in Valles Marineris. MOC images show that there are different thicknesses and types of layers, some with different albedo and some with different resistance to erosion. In other areas a complex set of processes can be discerned in images. For example, partially denuded craters reveal a sequence of impact into horizontal layers, subsequently covered by a thick friable layer that has now been partially removed, probably by aeolian activity and possibly continuing at the present time. As the meaning of such images is unraveled, it is anticipated that we will achieve a better understanding of the period of geologic time near the end of heavy bombardment.

Preliminary analysis of the TES data after removal of atmospheric and dust components in the spectra (MD Smith et al 1999) suggests that there are two somewhat different but basically basaltic rock compositions whose distribution can be spatially mapped over the surface (Christensen et al 1999b). TES has discovered and mapped the distribution of basaltic rocks in the southern highlands of Mars and of andesitic rocks in the younger northern lowlands. Elemental analysis of rocks by Pathfinder indicated a more andesitic composition than the basalt that was analyzed at the Viking sites. This observed chemical difference helps to validate the spectroscopic indication of different basalt types. The infrared spectra demonstrate for the first time the abundant presence of plagioclase feldspar, the low abundance or lack of quartz, and the absence of a pervasively weathered surface, at least in the darker areas. Spectral mapping has established a unique area, $\sim 350$ by $350 \mathrm{~km}$, that contains abundant, relatively coarse-grained hematite (Christensen et al 1999a). The search for carbonates and sulfates has been fruitless despite careful analyses of nearly 20 million spectra. Albedo mapping shows that significant changes in the pattern of light and dark material have occurred since the Viking observations, which indicates current aeolian activity (Jakosky et al 1999). Both albedo and thermal inertia mapping are being carried out at higher resolution as the mapping mission proceeds. Figure 6 (see color insert) shows the 2:00 AM temperature of the Martian surface as measured by TES during the first three weeks of the mapping mission. The temperatures range from $-120^{\circ} \mathrm{C}$ to $-65^{\circ} \mathrm{C}$. The coldest regions are areas of very fine dust, which loses heat rapidly, and the warmest regions are areas of coarse sand, gravel, and rocks. The Valles Marineris is clearly visible as a warm region, as are most of the northern plains, indicative of their typical surface. The very cold regions in the south mark the south polar frost cover.

The high-resolution images of MOC show an incredible abundance of depositional aeolian landforms_-dunes, sandsheets, and mantling drifts. However, the nature and origin of the surface soil, sand, and dust remain unresolved. The Viking Landers showed that the soils had high iron, sulfur, and chlorine contents, and that the soil particles are strongly magnetic, probably due to a magnetic iron 
mineral acting as a reddish pigment. In the past, the soils were generally interpreted as secondary weathering products of mafic igneous rocks such as smectite, possibly resulting from palagonitization of basalt. In general, the Pathfinder results only confirmed the Viking observations. However, a high abundance of weathering minerals is not confirmed by remote sensing observations. Ruff \& Christensen (1999) have shown that infrared spectra for the bright and dark albedo patches on Mars are well matched by a fine and a coarse aggregate, respectively, of pyroxene and plagioclase. Thus the bright regions as well as the dark regionsand much of the soil and dust - may simply be basaltic material, ground up by impact processes or physical weathering and not involving hydrolytic or sulfuric alteration at all. The light-colored dunes may simply consist of sand-sized aggregate particles. Nevertheless, a more thorough understanding of the nature and origin of the soil, sand, and dust remains a major goal.

\section{Structure and Dynamics of the Atmosphere}

Although Earth and Mars have evolved atmospheres with very different compositions, it could be predicted — and has been shown — that they have similar global circulation patterns (Haberle 1986). Both have atmospheres that are nearly transparent to sunlight and store almost no heat. Sunlight passes through the atmosphere without heating it and then heats the surface, which then heats the atmosphere from below. The absence of an ocean, which would buffer surface temperature changes, and the fact that carbon dioxide has higher thermal emission than nitrogen means that the atmospheric temperature of Mars responds rapidly to daily changes and seasonal changes in solar input. Figure 7 (see color insert) shows 2 AM and 2 PM surface temperatures and 2 PM atmospheric temperatures, as measured by TES on the night side and day side portions of the orbits in a single day. Both planets have an obliquity that leads to significantly more heating of the surface in the tropics than in the poles; the resulting temperature gradient produces a pressure gradient that drives a north-south (meridional) circulation. Both have a similar rotation rate, which determines the magnitude of the Coriolis force deflecting the moving air masses. Air rises where the solar heating is strongest, and then moves toward the poles and cools, sinking in the subtropics to form circulating cells (the Hadley cells). On Mars, in the absence of oceans, the rising branch closely follows the solar point, possibly as far as $25^{\circ}$ from the equator, and may lead to a single trans-equatorial Hadley cell during part of the year. The Coriolis force deflects the northern moving upper branch to the east (the westerlies) and the equatorward-moving lower branch to the west (the easterly trade winds).

At mid- and high latitudes, winds are predominately from the west, both at the surface and aloft. A band of intense winds-the jet stream-blows in the upper atmosphere at an altitude of $\sim 30-40 \mathrm{~km}$. Nearer the surface, high- and low-pressure storm systems migrate eastward, their swirling winds transporting heat toward the poles like the Hadley cells. These storms are more regular in their 
timing on Mars, probably because of the more rapid response of the atmosphere to temperature perturbations. The strength of the jet stream depends on the latitudinal surface temperature gradient, which on Earth tends to be buffered by the oceans. But on Mars, in winter the seasonal polar cap extends to the mid-latitudes, and the high temperature contrast between carbon dioxide ice and adjacent soil leads to jet streams many times stronger than on Earth. In summer, however, when the ice cap recedes the surface soil has a more uniform temperature, and the jet stream and the associated low-level storms disappear.

The highly elliptical orbit of Mars means that its seasons are of unequal duration and intensity. Compared with the northern seasons, the southern spring and summer are short and hot, and the fall and winter are long and cold. At perihelion, Mars receives about $40 \%$ more solar input than at aphelion; the difference for Earth is only about $3 \%$. This asymmetry has some influence on the structure and dynamics of the atmosphere, but has major influence on the seasonal cycles of carbon dioxide, of dust, and of water. Mars is unique in that almost $25 \%$ of its atmosphere cycles in and out of the carbon dioxide ice polar caps each year, causing a like global variation in atmospheric pressure as in surface pressure. Because of the longer fall and winter, the south polar ice cap grows larger than the north polar cap, and reaches a latitude of about $45^{\circ}$.

Models of the general circulation of the atmosphere of Mars have been developed by a number of groups (Haberle 1999, Allison et al 1999, Lewis \& Read 1999). These numerical models have reached a high level of maturity, but they had been based on surprisingly few data. For example, the "classic" but incomplete temperature profile from pole to pole has been replaced by hundreds of TES profiles that already provide spatial and temporal coverage over more than half the Martian year. Conrath et al (1999a,b) presented these initial data in the form of zonal profiles of mean temperature from pole to pole and the resultant calculated thermal winds. Radio occultation measurements are providing hundreds of precise vertical profiles of temperature and pressure in the lower atmosphere (Hinson et al 1999). Such data confirm the existence of cross-equatorial Hadley circulation during part of the year, as predicted by models. The basic numerical models typically used a fixed amount of dust uniformly distributed in the atmosphere to provide some direct warming of the atmosphere in order to match measured temperatures. More recent models have injected dust into the model at particular times and locations or under appropriate conditions of calculated surface stress. New data provide an intercomparison of atmospheric temperatures derived from ground-based millimeter, TES, and Viking data, providing information on seasonal and interannual variability of temperature and dust loading (Clancy 1999, Clancy et al 1999, Smith MD et al 1999). Observations show that the atmosphere can change rapidly from warm and dusty to cool and clear, and water ice clouds are seen to be nearly ubiquitous (Pearl et al 1999). The radiative effects of the water ice clouds and of the carbon dioxide ice clouds seen in the polar regions will have to be included in future modeling. 
Observations during the period of aerobraking of MGS provided new insight into the physical processes connecting the upper and lower atmospheres of Mars (Bougher \& Keating 1999). MGS aerobraking witnessed the onset, rise, and decay of a regional dust storm in the southern hemisphere. Rapid heating and expansion of the lower hemisphere increased faster than the actual increase in dust content. Accelerometer densities at $130 \mathrm{~km}$ increased by a factor of almost three over a 2-3 day period, as the atmosphere expanded by about $8 \mathrm{~km}$. The decay of the effects of the storm took almost two months. Continued observations have led to the discovery of a complex density wave structure in the upper atmosphere.

Topography is a major boundary condition for global circulation models, and the MOLA altimetry data are just now being incorporated into those models. The large relief near the dichotomy boundary and in the Tharsis region should strongly affect the lower branch of the Hadley circulation cell. Detailed topography of both polar regions and of the Hellas and Argyre basins is facilitating an understanding of the role of downslope winds in initiating dust storms. We can also expect that the detailed thermal inertia maps, indicative of local differences in daily cooling and heating rates, will also be incorporated into the models.

\section{Seasonal Cycles of Carbon Dioxide, Water, and Dust}

As indicated in the preceding section, the general circulation of the present Mars atmosphere couples together the seasonal cycles of carbon dioxide, water, and dust.

Most obvious, of course, is the waxing and waning of the seasonal carbon dioxide ice caps as nearly a quarter of the atmosphere alternately precipitates and sublimates from the surface. The abundance of water in the atmosphere is closely coupled with the cycle of carbon dioxide. The maximum abundance of water occurs during summer over the north pole. The permanent (residual) water-ice cap becomes a source of atmospheric water during the summer when the seasonal carbon dioxide frost has sublimated away and exposed the water ice. Viking observations suggested that water ice was not exposed at the southern ice cap in summer, but that the southern cap remained covered by carbon dioxide frost. If so, it would be a water vapor sink growing at the expense of the northern cap. Whether the carbon dioxide ice cover survives every summer is not clear, but observations over the period of the Mars Surveyor Program should clarify this issue.

The permanent polar ice caps are the largest known reservoirs of water on Mars. Visually, the high albedo southern cap appears smaller, but new topography indicates that ice, in part covered by dust, forms a tabular disc extending from each pole to about $85^{\circ}$ with a relief of about 800-1000 $\mathrm{m}$ at the edge (Zuber et al 1998b, Smith DE et al 1999a). The similarity in topographic profiles and the comparative rheology of water ice and carbon dioxide ice suggest that both caps consist predominantly of water ice. The permanent south polar cap is water ice, rather than carbon dioxide ice as was previously believed. Depending on the 
assumptions used, the northern cap has a volume of $1-2 \times 10^{6} \mathrm{~km}^{3}$ (Zuber et al $1998 \mathrm{~b}$ ) and the southern cap has a volume of $2-3 \times 10^{6} \mathrm{~km}^{3}$ (Smith DE et al 1999a). A large but unknown volume of water is stored as ground ice, and most models of the seasonal behavior of water include a substantial seasonal interchange of water between the regolith and the atmosphere.

The dust cycle is very closely coupled with the general circulation because of the feedback between dust lifting and the intensity of circulation. Dust raised by the winds tends to intensify the winds in a feedback manner, because the dust absorbs solar radiation and then heats the atmosphere directly. MGS showed that the onset of a dust storm in the southern hemisphere was observed within days as a marked pressure increase in the upper atmosphere of the northern hemisphere. Global dust storms occur predominantly during the southern spring and summer when Mars is near perihelion, because that is when the heating of its atmosphere and the intensity of circulation are greatest. Viking measurements of the attenuation of sunlight indicated that the atmosphere never completely cleared of dust. However, MGS has also shown that water-ice clouds are abundant, which contributes to the attenuation of sunlight, and in addition must play some role in controlling the vertical abundance of dust.

An important finding of MGS is the extent to which aeolian processes have modified the surface (Malin et al 1998). Almost everywhere one looks there is evidence of atmospheric-surface interaction in the form of dunes, sand sheets, wind erosion features, and even active dust devils (Metzger et al 1999) and small localized storms. In several places it has been shown that sand transport is presently occurring. In general, dust is not lofted directly-it requires very strong wind - but it is probably injected into the air during saltation of sand-sized material. In the past, our thinking may have attributed the bulk of atmospheric dust to the slow settling of fine dust after great storms, but the role of small and regional dust storms - a continuum of scales-will now have to be considered. Models of surface stress using the new high-quality topography will predict locations of evolving dust storms, and these predictions will have to be confirmed by visual observation (Anderson et al 1999). This approach should help to clarify some major questions: Why isn't there a global storm every year, and what shuts off the storm once it starts? What are the mechanisms and processes that determine whether a large local storm dies, or whether it grows into a regional or even a planet-encircling storm?

The layering in the polar deposits provides evidence that settling of dust and ice is, and has been, an important process. It can be assumed that dust particles form nuclei for water and carbon dioxide ice precipitation at times, but the importance and timing of this process in the seasonal cycles of dust, water, and carbon dioxide is not clear. The high-albedo residual ice cap overlies layered depositsthick stacks of alternating light and dark layers with individual bands extending down to the limit of resolution. Residual ice dominates near the pole, and layered deposits become more abundant away from the pole-within troughs that form the distinctive swirl pattern, and as a continuous feature around the edge of the 
cap. The composition of the layers is uncertain, but wide proportions of red dust, sand, ice, and void space have been suggested. On the periphery are circumpolar deposits, commonly mantled by dunes and sand sheets. Fretted features and the shapes of craters indicate that these deposits also contain or are underlain by abundant ice. New topography of this area in the southern hemisphere has been obtained; within weeks, images from MGS will also be available as the sun reaches the southern polar region, and at year's end the landing of MPL will provide an increased understanding of this region of Mars.

\section{Water on Mars}

Water as a vapor and solid, when not in the sunlight, can be present in the atmosphere and polar regions of Mars, but liquid water is not stable under present atmospheric conditions.

Calculations indicate that ground ice should be stable throughout much of the year in the mid-latitudes, and over the entire year in the polar regions. Observations of patterned groups indicate the current or recent presence of ground ice in the soil. Abundant evidence has been presented to show that water also existed in the past, in the form of ground ice and groundwater-at times catastrophically released-and possibly even as standing bodies of water (Carr 1996). The channels provide the most dramatic evidence for water on Mars; water emerged from the highlands' subsurface, carved channels as it flowed downstream, and emptied into the northern lowlands, where the broad channels end abruptly, possibly debouching into a body of water. Less dramatic are the smaller valley networks, whose pattern suggested the possibility that they were formed by surface runoff from rainfall or melting ice during a climatic period when the atmosphere was dense enough and warm enough to stabilize liquid water. High weathering rates would then lead to rapid collection of the carbon dioxide into the ground as carbonates.

Most aspects of the water and climate story on Mars will remain controversial until much more analysis of the new information has been carried out. MOC images and detailed topography are increasing the understanding of the outflow channels and their source. Eventually, this will lead to understanding of the heat source and the volume of ice that had to be melted to provide the necessary water, and of the timing of these events in the various channels. As yet, MOC images provide little evidence (Malin \& Edgett 1999b) for the proposed shoreline of an extensive ocean (Parker et al 1989), but the detailed altimetry suggests the presence of a bench at constant altitude around the lowest parts of the northern plains, as shown in Figure 3 (color insert) (Head et al 1998). Patterned ground and crater characteristics suggest the presence of ground ice within the northern plains, possibly residual from a large body of water.

The high-resolution MOC images have shown that the valley networks seen in the Viking images are typically not dissected with the hierarchy of tributaries characteristic of valley networks formed from surface runoff (Malin \& Carr 1999). 
Instead, they terminate in stubby branches, typical of valley networks in regions of groundwater sapping or of thermokarst terrain. However, some MOC images do show sinuous patterns suggestive of sustained fluvial flow and erosion over a period of time, possibly under an ice cover. It should be recognized that it took many years of study of the Viking and Mariner 9 images to achieve our current understanding of these processes; clearly, it will also take a long time to study the tremendous number of MOC images that have been and will be returned to Earth. The difference with time is that now readers of this paper can quickly retrieve these images for themselves electronically and make their own interpretation.

Despite the ambiguity in interpreting the valley networks, it still seems that there is an apparent change in the modification rate of craters early in Mars' history, near the end of the heavy bombardment. This observation retains the possibility of the current thinking: that for most of the period of heavy bombardment Mars was warm and wet and had a thick atmosphere, and toward the end of this period the atmosphere thinned considerably as carbon dioxide was removed and the surface cooled. Thus, the ongoing search for carbonate deposits on the surface, although so far fruitless, remains very important to the interpretation of the history of water on Mars.

It is generally understood that the presence of liquid water is critical to the evolution and retention of life. For this reason, NASA's Mars Program has identified the increase of our understanding of the history of water on Mars as its principal cross-cutting and unifying theme. Many of the orbiter observations are directed toward trying to identify places where liquid water may have existed in the past-i.e. shorelines, hot spring deposits, carbonate deposits, etc. Such areas would have a high priority for future sample return missions that would seek evidence of past life on Mars. Clearly, liquid water, derived from ground ice, has had an ephemeral presence. However, the new observations do seem to push any warmer and wetter climate period farther back into the period of heavy bombardment. At this point, we are a long way from understanding that critical period in Mars' history. How did ground ice become widely distributed? How was it recycled-or did it get recycled at all? Was it originally distributed in such abundance so as to provide sufficient water to carve all the outflow channels?

\section{ACKNOWLEDGMENTS}

Working with all the scientists and engineers associated with the Mars Observer and Mars Global Surveyor projects over the last 20 years has been a rewarding and unbelievable learning experience. More than 400 attendees at the Fifth International Conference on Mars in July 1999 helped to shape this summary, but I particularly want to thank the invited speakers who presented specialized reviews and prepared extended abstracts (CD-ROM Contribution, 972. The Lunar \& Planetary Institute. Houston, Texas). In many instances where I used these abstracts, I have actually cited recent or "In press" papers to acknowledge the contribution. 
Visit the Annual Reviews home page at www.AnnualReviews.org.

\section{LITERATURE CITED}

Acuna MH, Connerney JEP, Ness NF, Lin RP, Mitchell D, et al. 1999. Global distribution of crustal magnetization discovered by the Mars Global Surveyor MAG/ER experiment. Science 284:790-93

Acuna MH, Connerney JEP, Wasilewski P, Lin RP, Anderson KA, et al. 1998. Magnetic field and plasma observations at Mars: initial results of the Mars Global Surveyor mission. Science 279:1676-80

Albee AL, Palluconi FD, Arvidson RE. 1992. Mars Observer mission. J. Geophys. Res. 97:7665-80

Albee AL, Palluconi FD, Arvidson RE. 1998. Mars Global Surveyor mission: overview and status. Science 279:1671-72

Allison M, Ross JD, Solomon N. 1999. Mapping the Martian meteorology. In The $5^{\text {th }}$ International Conference Mars, Abstr. \# 6102, LPI Contrib. 972. Houston, TX: Lunar and Planetary Institute (CD-ROM)

Anderson FS, Greeley R, Xu P, Lo E, Blumberg DG, et al. 1999. Assessing the Martian surface distribution of aeolian sand using a Mars general circulation model. J. Geophys. Res. Planets 104:18991-9002

Bills BG, Ferrari AJ. 1978. Mars topography, harmonics and geophysical implications. $J$. Geophys. Res. 83:3497-508

Bertka C, Fei Y. 1997. Mineralogy of the Martian interior up to core-mantle pressures. $J$. Geophys. Res. 102:5251-64

Bertka C, Fei Y. 1998a. Density profile of an SNC Martian interior and the moment of inertia factor of Mars. Earth Planet. Sci. Lett. 157:79-88

Bertka C, Fei Y. 1998b. Implications of Mars Pathfinder data for the accretion history of the terrestrial planets. Science 281:1838-40

Bertka C, Fei Y, 1999, Geophysical and geochemical constraints on the composition and structure of the Martian interior. In The $5^{\text {th }}$ International Conference Mars, Abstr. \# 6225, LPI Contrib. 972. Houston, TX: Lunar and Planetary Institute (CD-ROM)

Bogard, DD. 1982. Trapped noble gases in the EETA 79001 shergottite. Meteoritics 17:185-86

Bougher SW, Keating GM. 1999. Structure of the Mars upper atmosphere: MGS aerobraking data and model interpretations. In The $5^{\text {th }}$ International Conference Mars, Abstr. \# 6010, LPI Contrib. 972. Houston, TX: Lunar and Planetary Institute (CDROM)

Carr, MH. 1996. Water on Mars. New York: Oxford Univ. Press. 229 pp.

Christensen PR, Bandfield JL, Smith MD, Hamilton VE. 1999a. Identification of a basaltic component on the Martian surface from Thermal Emission Spectrometer data. J. Geophys. Res. Planets. In press

Christensen PR, Clark RL, Kieffer HH, Malin MC, Pearl JC, et al. 1999b. Detection of crystalline hematite mineralization on Mars by the Thermal Emission Spectrometer: evidence for near-surface water. J. Geophys. Res. Planets. In press

Clancy RT. 1999. Orbital and interannual variability of the global Mars atmosphere. In The $5^{\text {th }}$ International Conference Mars, Abstr. \# 6023, LPI Contrib. 972. Houston, TX: Lunar and Planetary Institute (CDROM)

Clancy RT, Sandor BJ, Wolff MJ, Christensen PR, Smith MD, et al. 1999. Comparisons of Mars atmospheric temperatures retrieved from ground-based millimeter and Mars Global Surveyor infrared measurements. $J$. Geophy. Res. Planets. In press

Conrath BJ, Pearl JC, Smith MD, Banfield D, Christensen PR. 1999a. Observations of the thermal structure and dynamics of the Martian atmosphere. In The $5^{\text {th }}$ International 
Conference Mars, Abstr. \# 6015, LPI Contrib. 972. Houston, TX: Lunar and Planetary Institute (CD-ROM)

Conrath BJ, Smith MD, Pearl JC, Christensen PR. 1999b. Mars Global Surveyor Thermal Emission Spectrometer (TES) observations: atmospheric temperatures during aerobraking and science phasing. J. Geophys. Res. Planets. In press

Connerney JEP, Acuna MH, Wasilewshi PJ, Ness NF, Reme H, et al. 1999. Magnetic lineations in the ancient crust of Mars. Science 284:794-98

Dreibus G, Wanke H. 1985. Mars: a volatile rich planet. Meteoritics 20:367-82

Folkner WM, Yoder CF, Yuan DN, Standish EM, Preston RA. 1997. Interior structure and seasonal mass redistribution of Mars from radio tracking of Mars Pathfinder. Science 278:1749-52

Golombek MP. 1997. The Mars Pathfinder mission. J. Geophys. Res. 102:3953-65

Golombek MP, et al. 1999. Overview of the Mars Pathfinder mission: launch through landing, surface operations, data sets, and science results. J. Geophys. Res. 104:852353

Greeley R, Bridges NT, Crown DA, Crumpler LS, Fagents SA, et al. 1999. Chapter 4: Volcanism on the Red Planet: Mars. In Environmental Effects on Volcanic Eruptions: From Deep Oceans to Deep Space. New York: Plenum. In press

Haberle RM. 1986. The climate of Mars. Sci. Am. 254:54-62

Haberle RM. 1999. Modeling the atmospheric structure and dynamics of the Martian atmosphere. In The $5^{\text {th }}$ International Conference Mars, Abstr. \# 6018, LPI Contrib. 972. Houston, TX: Lunar and Planetary Institute (CD-ROM)

Hartmann WK, Malin MC, McEwen A, Carr MC, Soderblom L, et al. 1999. Evidence for recent volcanism on Mars from crater counts. Nature 397:586-89

Head JW III, Kreslavsky M, Hiesinger H, Ivanov M, Pratt S, et al. 1998. Oceans in the past history of Mars: tests for their presence using Mars Orbiter Laser Altimeter (MOLA) data. Geophys. Res. Lett. 25:4401-4

Hinson DP, Flasar FM, Simpson RA, Twicken JD, Tyler GL. 1999. Initial results from radio occultation measurements with Mars Global Surveyor. J. Geophy. Res. Planets. In press

Jakosky BM, Mellon MT, Kieffer HH, Christensen PR, Varnes ES, Lee SW. 1999. The thermal inertia of Mars from the Mars Global Surveyor Thermal Emission Spectrometer. J. Geophys. Res. Planets. In press

James PB, Lee SW. 1999. Hubble space telescope observations of planets and satellites. Annu. Rev. Earth Planet. Sci. 27:115-48

Lewis SR, Read PL. 1999. Data assimilation for the atmosphere of Mars. In The $5^{\text {th }}$ International Conference Mars, Abstr. \# 6105, LPI Contrib. 972. Houston, TX: Lunar and Planetary Institute (CD-ROM)

Longhi J, Knittle E, Holloway JR, Wanke H. 1992. The bulk composition, mineralogy, and internal structure of Mars. In MARS, ed. HH Kieffer, BM Jakosky, CW Snyder, MS Matthews, pp. 184-208. Tucson: Univ. Ariz. Press. 1498 pp.

Longhi J. 1999. SNC meteorites and the bulk composition of Mars. In The $5^{\text {th }}$ International Conference Mars, Abstr. \# 6027, LPI Contrib. 972. Houston, TX: Lunar and Planetary Institute (CD-ROM)

Malin MC, Carr MH. 1999. Groundwater formation of Martian valleys. Nature 397:589-91

Malin MC, Carr MH, Danielson GE, Davies ME, Hartmann WK, et al. 1998. Early views of the Martian surface from the Mars Orbiter camera of Mars Global Surveyor. Science 279:1681-85

Malin MC, Edgett KS. 1999a. An emergent, new paradigm for Mars geology. In The $5^{\text {th }}$ International Conference Mars, Abstr. \# 6027, LPI Contrib. 972. Houston, TX: Lunar and Planetary Institute (CD-ROM)

Malin MC, Edgett KS. 1999b. Oceans or seas in the Martian northern lowlands: high res- 
olution imaging tests of proposed coastlines. Geophys. Res. Lett. 26:3049-52

McEwen AS, Malin MC, Carr MH, Hartmann WK. 1999. Voluminous volcanism on early Mars revealed in Valles Marineris. Nature 397:584-86

McKay D, Gibson E, Thomas-Keprta K. 1999. Possible evidence for life in ALH84001. In The $5^{\text {th }}$ International Conference Mars, Abstr. \# 6211, LPI Contrib. 972. Houston, TX: Lunar and Planetary Institute (CDROM)

McKay DS, Gibson EK, Thomas-Keprta KL, Vail H, Romanek CS, et al. 1996. Search for past life on Mars: possible relic biogenic activity in Martian meteorite ALH84001. Science 273:924-30

McSween HY. 1994. What have we learned about Mars from SNC meteorites? Meteoritics 29:757-79

Metzger SM, Carr JR, Johnson JR, Parker TJ, Lemmon MT. 1999. Dust devil vortices seen by the Mars Pathfinder camera. Geophys. Res. Lett. 26:2781-84

Parker TS, Saunders RS, Schneeberger DM. 1989. Transitional morphology in West Deuteronilus Mensae, Mars: implications for modification of the lowland/highland boundary. Icarus 82:111-45

Pearl JC, Smith MD, Bandfield JL, Christensen PR. 1999. Mars Global Surveyor Thermal Emission Spectrometer (TES) observations of water-ice clouds during aerobraking and science phasing. J. Geophys. Res. Planets. In press

Pike W, Bertka CM, Fei Y. 1999. Melting temperatures in the Fe-Ni-S system at high pressure: implications for the state of the Martian core. In Lunar and Planetary Science Vol. 30. Abstr. 1489. Houston, TX: Lunar and Planetary Institute (CD-ROM)

Ruff SW, Christensen, PR. 1999. Thermal infrared spectral characteristics of the Mar- tian albedo features: clues to composition. In The $5^{\text {th }}$ International Conference Mars, Abstr. \#6230, LPI Contrib. 972. Houston, TX: Lunar and Planetary Institute (CDROM).

Smith DE, Zuber MT, Solomon SC, Phillips RJ, Head JW, et al. 1999a. The global topography of Mars and implications for surface evolution. Science 284:1495-502

Smith DE, Sjogren WL, Tyler GL, Balmino G, Lemoine FG, Konopliv AS. 1999b. The gravity field of Mars: results from Mars Global Surveyor. Science 286:94-97

Smith, MD, Bandfield JL, Christensen PR. 1999. Separation of atmospheric and surface spectral features in Mars Global Surveyor Thermal Emission Spectrometer (TES) spectra: models and atmospheric properties. J. Geophys. Res. Planets. In press

Treiman AH. 1999. Biomarkers in ALH84001. In The $5^{\text {th }}$ International Conference Mars, Abstr. \# 6019, LPI Contrib. 972. Houston, TX: Lunar and Planetary Institute (CDROM)

Tsuruda, K. 1999. Proc. Nozomi Workshop. Inst. Space \& Astronaut. Sci., Jpn. April 26-28.

Zuber MT, Smith DE, Phillips RJ, Solomon SC, Banerdt WB, et al. 1998a. Shape of the northern hemisphere of Mars from the Mars Orbiter Laser Altimeter (MOLA). Geophys. Res. Lett. 25:4393-96

Zuber MT, Smith DE, Solomon SC, Abshire JB, Afzal RS, et al. 1998b. Observations of the North Polar Region of Mars from the Mars Orbiter Laser Altimeter. Science 282:2053-60

Zuber MT, Smith DE, Tyler GL, Solomon SC, Phillips RJ, et al. 1999. The internal structure and early evolution of Mars from Mars Global Surveyor. AGU fall meet. (Abstr.) In press 


\section{CONTENTS}

Palynology after Y2K--Understanding the Source Area of Pollen in Sediments, M. B. Davis

Dinosaur Reproduction and Parenting, John R. Horner

Evolution and Structure of the Lachlan Fold Belt (Orogen) of Eastern

Australia, David A. Foster, David R. Gray

Remote Sensing of Active Volcanoes, Peter Francis, David Rothery

Dynamics of Volcanic Systems in Iceland: Example of Tectonism and Volcanism at Juxtaposed Hot Spot and Mid-Ocean Ridge Systems, Agust Gudmundsson

Understanding Oblique Impacts from Experiments, Observations, and Modeling, E. Pierazzo, H. J. Melosh

Synthetic Aperture Radar Interferometry to Measure Earth"s Surface Topography and Its Deformation, Roland Bürgmann, Paul A. Rosen, Eric J. Fielding

Geologic Evolution of the Himalayan-Tibetan Orogen, An Yin, T. Mark Harrison

MARS 2000, Arden L. Albee

Vredefort, Sudbury, Chicxulub: Three of a Kind, Richard Grieve, Ann Therriault

Climate Reconstruction from Subsurface Temperatures, Henry N.

Pollack, Shaopeng Huang

Asteroid Fragmentation and Evolution of Asteroids, Eileen V. Ryan

Seismic Imaging of Mantle Plumes, Henri-Claude Nataf

New Perspectives on Orbitally Forced Stratigraphy, Linda A. Hinnov

Clathrate Hydrates, Bruce A. Buffett

Heterogeneity of the Lowermost Mantle, Edward J. Garnero

Spreading Volcanoes, Andrea Borgia, Paul T. Delaney, Roger P.

Denlinger

Scaling, Universality, and Geomorphology, Peter Sheridan Dodds,

Daniel H. Rothman

Chemical Weathering, Atmospheric CO2, and Climate, Lee R. Kump,

Self-Ordering and Complexity in Epizonal Mineral Deposits, Richard W. Henley, Byron R. Berger 